\title{
Broad-scale patterns across the languages of the Andes and Amazonia
}

Paul Heggarty

\section{Themes and structure}

This chapter provides an overview of the broadest-scale perspectives that linguistics can offer on our theme of an Andes-Amazonia divide. It follows the same contrast as in Chapter 1.2, between two fundamental and opposing linguistic concepts, each with their corresponding signals of the human past. Section 2 looks at language families, created by and attesting to past processes of geographical expansion and divergence. Section 3 looks at linguistic convergence, attesting to processes of interaction between past societies. Section 4 concludes by stepping back to a final, broadest, worldwide perspective on the validity of a divide between the languages of the Andes and of Amazonia.

\section{Language families: Expansions and divergence}

Respecting or bridging the Andes-Amazonia divide?

As already explored at the start of Chapter 1.2, the most far-dispersed language family in South America is Arawak. Although considered quintessentially Amazonian, it nonetheless ranges far beyond Amazonia proper. This only makes it all the more telling, then, that the one environmental frontier that it did balk at was that between Amazonia and the Andes (see section 3 below, for the borderline case of Yanesha, spoken up to 1,800 $\mathrm{m}$ in central Peru). But what of the other three main language families of lowland South America? The Tupí family was similarly very expansive within Amazonia and beyond, along the coast of Brazil and into the Chaco. It includes notably the Guaraní language, spoken particularly in Paraguay and lowland Bolivia. But like Arawak, Tupí has not significantly crossed the frontier into the Andes (see Figure 3.4.1). The next main family, Carib, is likewise spoken 


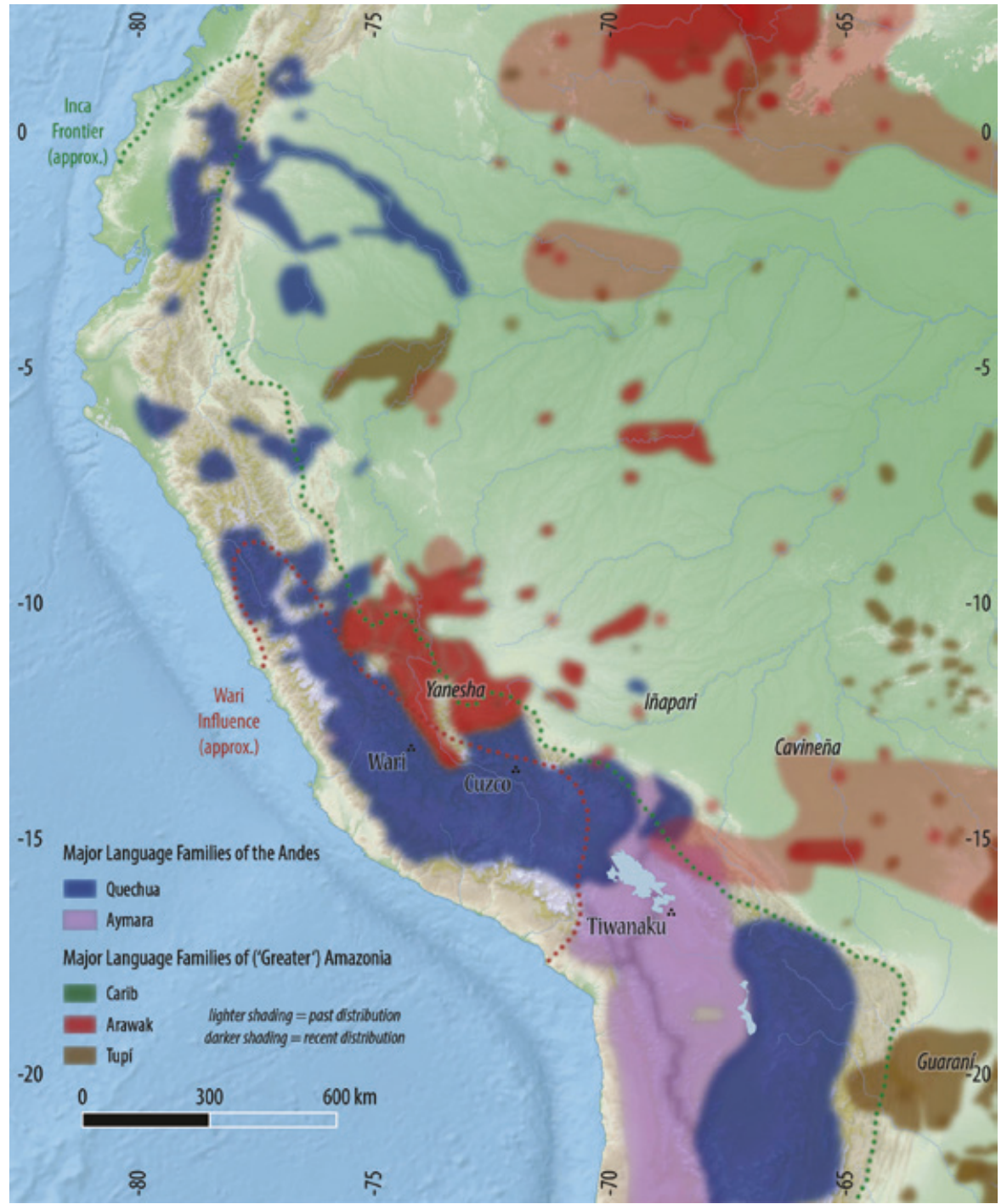

Figure 3.4.1 Map of major language families along the Andes-Amazonia transition. (C) Paul Heggarty.

almost exclusively in the lowlands, except for a few forms that spread to somewhat higher elevations in northern Colombia. Brazil does count one other main indigenous family, Jê (or 'Macro-Jê', in various hypotheses that extend it to a few other individual languages), but it is of less relevance here since it is mostly distributed outside the Amazonian rainforest itself, to its south-west.

Greater Amazonia does host many more language families, scattered over geographical scales that are relatively smaller, although still of the order of 500-1,000 km for families like Pano, Tacanan and Tukanoan, for example (see 


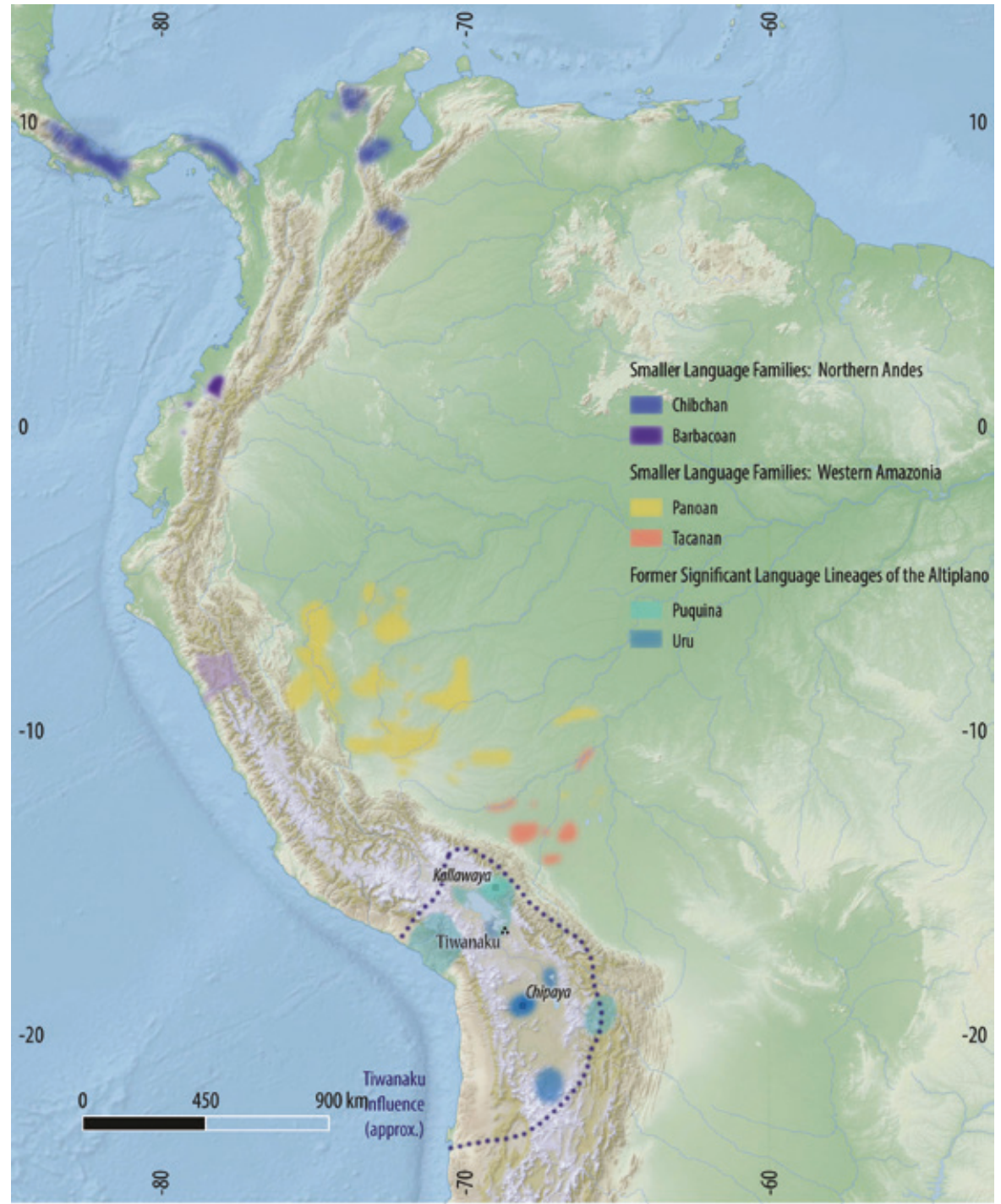

Figure 3.4.2 Map of smaller language families of the Andes and western Amazonia. (C) Paul Heggarty.

Figure 3.4.2). Despite that, and despite their presence up to the very westernmost edges of Amazonia, again no languages of these families are found in the neighbouring Andes. In Ecuador, the highlands do at least host occasional placenames, as well as loanwords and some structural features in the local forms of Quechua, that have been hypothesized to derive from languages originating in Amazonia. It is not excluded, then, that some Amazonian families may once have had some presence higher into the Andes than today. Most of the indications are limited and tenuous, however, and only further research may confirm or disconfirm them 
convincingly. Our knowledge of the pre-Quechua languages of highland Ecuador is very patchy (Adelaar and Muysken 2004, 392-7), and the strongest case that can be made is for a wider past distribution here of the Barbacoan family. That survives today in southern Colombia and northern Ecuador, and not just in highland but also in lowland regions - although tellingly, in the lowlands of the coastal, Pacific side of the Andes, not in the Amazonian Oriente.

It was noted in Chapter 1.2 that by far the most widespread language family of the highlands, likewise, does generally respect the Andes-Amazonia divide, from the other side. Quechua spread very much north-south, along the Andes, rather than east-west (see Figure 3.4.1). So too did the Inca Empire, but the superficial correlation is deeply misleading if interpreted as causation - that is, as if the language distribution were only a result of Inca rule. This is clear from the profound mismatch in chronology. The initial expansion and divergence phases of the Quechua family go back many centuries before the Incas (Beresford-Jones and Heggarty 2012b). Tawantinsuyu seems to have been (in part) responsible only for the main two Quechua expansions beyond Peru itself, northwards into highland Ecuador and south-eastwards (beyond Aymara) into highland Bolivia. Far-flung as they were, these movements were still constrained to the highlands, and so do indeed mirror the Incas' reluctance to venture deep into the lowlands (Chapter 5.1). Moreover, these late Quechua expansions were further driven by Spanish colonial rule, again broadly respecting the Andes-Amazonia frontier (Chapter 5.3). In short, if a causation is sought for the rough correlation in geographical scope between the distributions of Quechua and of the Inca Empire, then it is not so much that the latter shaped the former, but that both were shaped by the same underlying context: the Andes-Amazonia divide.

Yet although Quechua remains quintessentially a highland family, there is one significant exception to this, in the northernmost part of its range. In Ecuador, forms of Quechua are spoken not just in the highlands but in the lowlands of the Oriente, too. Moreover, from there Quechua is also distributed downstream along the Napo and other parallel-flowing rivers into north-eastern Peru, to add to a scatter of further enclaves in the Amazonian provinces of San Martín and Loreto. This does not contradict the Incas' reluctance to enter Amazonia, however, because these lowland Quechua-speaking areas seem to have become established only later, during the Spanish colonial period. In fact, set against the general weakness of the Spanish footprint in the lowlands (Chapter 5.3), it is language that here turns out to provide a rare indication of an undeniable and striking cultural spread from the Andes into Amazonia.

Ironically, though, the mechanism that spread this indigenous language lineage was one of the very few real agents of European influence on the lowlands: missionary activity by Jesuits and Franciscans (Chapter 5.3). In particular, the reducciones policy gathered together diverse Amazonian populations who had no common language. To fulfil that role, and not least to provide a language through which to evangelize, European missionaries 'seeded' Quechua in these 
new mission communities, by bringing in speakers from the nearby highlands. The choice of Quechua was largely for the Europeans' own convenience, since it was the lingua franca that they were already using to communicate with and evangelize indigenous populations in the highlands (some of whom also retained their own diverse native tongues until well into the colonial era). The northernmost of all forms of Quechua, the 'Inga' variety in southern Colombia, is also spoken down into the Amazonian lowlands, and its origins remain somewhat unclear.

Much more recently, the last few decades have also seen some spill-over of highland languages, as speakers of them have migrated down from the Andes to claim new land for farming in Amazonia. Their languages have few prospects of ever becoming entrenched there, of course, as Spanish now spreads at the expense of all indigenous languages. In pre-Columbian times, though, there is no good evidence for any significant Quechua presence in Amazonia.

The other significant language family in the highlands, Aymara, likewise seems to observe the 'divide', just like all four major Amazonian ones. So, in sum, the distributions of all major language families do seem to support the reality of an Andes-Amazonia frontier. The only possible caveat is that there is at least a hypothesis, albeit tentative, that one notable Andean language, Puquina, may in fact have very deep roots in Amazonia, and be distantly related to Arawak. The potential significance is clear for the Andes-Amazonia divide - although it should be noted that there is controversy not just on the claim itself, but on whether the issue can ever really be settled, given how little we actually know of the now extinct Puquina. The case is taken up in more detail in Chapter 4.1.

Language families can also contribute other valuable perspectives on the Andes-Amazonia divide, besides ostensibly observing some taboo on trespassing across it. For the families on either side present quite distinct panoramas on other levels, too: in the patterns of their geographical distributions, in the size of their speaker populations and in how far back in time their expansion histories go. We now take each of these in turn.

\section{Geographical patterns}

In Amazonia, each of the three main families - Arawak, Tupí and Carib - is curiously scattered and splintered across its whole extent, interspersed piecemeal with members of the other two, and with languages of many smaller families, as well as language isolates (Epps 2009). In the Andes, by contrast, Quechua occupies just a few large blocks of continuous territory (Cerrón-Palomino 2003): the Zona Continua from northern Ancash to Lake Titicaca (breaking up only now as the language cedes to Spanish); in the Ecuadoran highlands and into the Oriente; and in the southern and eastern highlands of Bolivia. Only in northern Peru, where it never appears to have been widely established, is Quechua found scattered in just small, isolated enclaves (Cañaris, Inkawasi, Cajamarca and Chachapoyas). As 
shown in Figure 3.4.1, one of the few breaks in the geography of Quechua is filled by another broad, continuous distribution, that of the other widespread Andean language family, Aymara (which formerly extended further across the southern highlands of Peru, where Quechua then replaced it). In short, the Andes-Amazonia frontier seems to mark a curious contrast also in how language families are distributed on either side: respectively, in large, coherent and exclusive blocks of territory, or scattered and splintered amongst each other.

\section{Demography, forced migrations and genetics}

A second major dimension of difference is demography. To judge from most recent census figures, Quechua counts c. 6-7 million speakers, Aymara about 1.9 million (Howard 2011). Arawak, by contrast, has only 750,000 speakers, Carib far fewer (Simons and Fennig 2018). Only Tupí has a similar demographic scale to Quechua, and much less evenly distributed, because the single language Guaraní accounts for the vast majority of the family's speakers. Obviously, such was the demographic cataclysm provoked by the advent of the Europeans and their pathogens, and such has been the scale of shift from indigenous languages to European ones, that modern population figures are not good indicators of past demography. That said, they do at least remain compatible with the traditional assumption that the intensive farming and complex societies of the Andes had come to support higher populations and densities than in Amazonia, and that would also have applied to their respective language families. The latest archaeological thinking in Amazonia, of course, would have us revise population figures for pre-Columbian Amazonia upwards by a huge factor (see Chapter 1.1). This is not for linguistics to judge, although it does leave to be explained the mismatch in the sizes of modern populations speaking indigenous languages of Amazonia and of the Andes.

On another aspect of demography, at least some of the main expansion phases of Quechua were clearly driven by very significant forced population movements, as historically reported under the regimes of Spanish colonialism (such as the Potosí draft) and the Incas (mit'a, yanakuna, imperial armies). Even the Jesuit and Franciscan missions that led to Quechua's footholds in Amazonia were in part forced population movements, if on a smaller scale. This brings us to a critical proviso, however, when inferring 'migrations' from branching structures in language family trees: it does not always have to be people who move en masse. As the New Archaeology would have it, ideas and culture can move, too. People can largely stay put, but switch to another language that itself is doing the expanding and 'migrating'. To be precise, a minimum number of speakers must move, but in particular circumstances (especially underlying linguistic diversity: see Heggarty 2015, 622-3) they need not be a demographic majority - as when European missionaries 'seeded' Quechua into their Amazonian reducciones through just a few native-speaker highlanders. 
Taken together, these observations are all at least compatible with another potential contrast between the Andes and Amazonia. The major language families of the Andes seem to have been driven at least in good part by demographic processes, shaped in turn by agricultural productivity and state-led interventions to that end (including forced migrations). On the traditional view that such state structures were less prevalent in Amazonia, then the main families there may have been spread more by cultural processes than by demographic ones. Again, though, that view is now directly challenged by the 'new archaeological orthodoxy' (Chapter 1.1) that no longer sees pre-Columbian Amazonia as so different from the Andes in these respects after all.

Languages can in fact bear certain tell-tale characteristics that tend to betray that a language lineage was at some point ('imperfectly') learnt by a population that had originally spoken other languages. There are a few such features, for example, in the Quechua spoken in enclaves in Peruvian and Ecuadoran Amazonia (and to an extent also in highland Ecuador). Some scope for interpretation still remains with such characteristics, however, so it is all the more valuable to combine the linguistics with an independent, complementary data source specifically on matters demographic, namely genetics. The key is not to assume any one-to-one link between language lineages and genetic ones, of course, but on the contrary to compare and contrast where they do match with where they do not - that is, where a language spread mostly by demographic or by cultural expansion, respectively. Ultimately, it should in principle be possible for linguistics and genetics, working intelligently together, to tease these apart, to confirm or refute this further potential contrast between the Andes and Amazonia: in the dominant mode of language family expansions in each, demographic versus cultural. In practice, both disciplines need first to achieve the data coverage and resolution necessary (see also Chapter 1.3), but the potential is already clear from existing illustrations on more localized scales, some already focused on the Andes-Amazonia divide, as explored here in Chapter 3.3.

\section{Time depth}

Finally, a third dimension is of scale not in geography or demography, but in time. Every language family has its own chronology, from whenever the geographical expansion began that took that family's ancestral proto-language beyond its homeland, to set the divergence clock ticking in different regions. Since changes and differences accumulate through time, in principle the greater the divergence between the languages within a family, the longer that family must have been diverging. But while a relative sequence of divergent branching and 'migration' events is often clear, putting narrow, absolute dates on them is near impossible. Language change is anything but clockwork, and not remotely akin to the natural laws of radiocarbon decay. Various methods have been proposed, and most found wanting. Arguably the most promising - Bayesian phylogenetic dating - is nonetheless highly controversial, and limited in South 
America, where the lack of a deep written record robs the method of the deeptime calibrations that it needs in order to work most reliably. (For more on these methods, see Heggarty 2014.)

At present we remain stuck with largely impressionistic estimates, within very wide confidence limits (and no firm quantitative estimate of those, either). Yet even such broad ranges are enough to show a clear contrast across the AndesAmazonia divide. The main expansive families in the Andes are relatively shallow in time-depth: Quechua is generally considered less diverse than Romance (whose divergence dates back only to the Roman Empire), and is thus normally assumed to have spread only within the last 1,500 years or so. Aymara is of a similar order (or only slightly older, on some dubious measures). The major Amazonian families, meanwhile, are generally taken to have begun spreading and diverging at least twice as far back in prehistory. Kaufman and Golla $(2000,52)$ report estimates of 3700 вр for Carib, 4500 вр for Arawak, and 5500-6000 вP for Tupí. Such figures are to be taken with a very large dose of salt: few linguists would dare commit even to the digit for the millennia (Heggarty and Renfrew 2014b). Nonetheless, in line also with impressionistic comparisons of the diversity within each family, the default assumption is that major language families trace their expansions back far earlier in Amazonia than they do in the Andes.

To put that more explicitly in terms of what it means for prehistory, we have here something of a reversal of traditional visions on the contrast between these two regions. For in order for any language to begin diverging into a family at all requires some powerful expansive process on a large geographical scale. Conditions to foster such expansions would seem to have arisen in Amazonia long before they did in the Andes, then - to judge from the time-depths of the surviving language families, at least. The only other possibility would be if late developments in the Central Andes had overwritten all traces of some much earlier language expansion(s), just as Quechua has overwritten much of the earlier Aymara spread, and as Spanish is now replacing both. It is unlikely that we will ever be able to rule this out, although in those parts of the Andes where we do have indications of the earlier linguistic panorama, such as in northern Peru, they support a picture of high diversity rather than any large, early families.

There are, of course, some claims to reach wider and deeper in time: the putative 'macro-families' that pepper outdated linguistic literature (especially around the 1960s). Chapter 2.3 explains why they lack any methodological support, are disregarded by orthodox linguistics, and are therefore not considered here.

\section{Bringing it together: Homelands and origins}

So if the main language families in Amazonia and in the Andes differ simultaneously in patterning, demography, expansion mode and time-depth, is there any broader, deeper explanation that brings all of these dimensions together? There is something of an Andes-Amazonia divide at least in how scholars have tried 
to explain how, when and why these families came to exist in the first place - by spreading at the expense of other languages.

In Amazonia, much is made of the role of rivers, perhaps understandably so. Firstly, as conduits for easy mobility, rivers have been invoked especially to explain the Arawak family and its distribution. For Hornborg (2005), Arawak was spread across a water-borne trade network, and thus mostly by cultural processes and adoption, rather than by some major population expansion and migration, and without needing any expansive 'state' society behind it. (Rivers have also been suggested as conduits for the contrasting process of language convergence, but the evidence seems poor: see van Gijn et al. (2017).) Secondly, rivers were crucial to subsistence regimes that came to rely on farming the rich alluvial soils along várzea floodplains. This would have led farming groups to spread primarily along major rivers (Denevan 2002), leaving hunter-gatherers pushed back into the terra firme forest interior. Certainly, that is where most language isolates are found today, not (yet) displaced by the main expansive families. The distribution of those families would thus be more logical and consistent than the patchwork it might first appear. Hypotheses on the homelands of the major lowland families have also inclined towards regions at the upper, western reaches of the Amazon basin (Epps 2009). Some have even ventured that it is simply easier to move long distances downstream rather than upstream. More substantially, the main connection drawn has been with the periphery of Amazonia as where several important food plants began to be farmed, spreading outwards (and downstream) from there (Dixon and Aikhenvald 1999).

In the Andes, homelands for the major language families and explanations for their expansions have typically been sought and framed in very different terms: by explicit association with complex societies and their signatures in the archaeological record (Torero 1972, 91-9; Torero 1984; Cerrón-Palomino 2003). Initial assumptions (outside linguistics) were that all Quechua was the work of the Incas spreading out of Cuzco, and that Tiwanaku spread Aymara. Those were based on present-day language distributions and have rightly been abandoned as anachronistic. But they have been replaced by hypotheses that effectively just redirect the associations to other complex societies and languages. Notably, the (pre-Inca) Wari Middle Horizon in Peru is linked by different scholars to the early expansions of either Aymara or Quechua, or both (see Heggarty and Beresford-Jones 2012), while its contemporary polity in the Altiplano, Tiwanaku, is now associated with spreading the Puquina language, now extinct (see Chapter 4.1, and Cerrón-Palomino 2013).

The first beginnings of agriculture play no significant role here, since they long pre-date any of the language family expansions that can be identified in the Andes. Rather, at their shallow time-depths, any potential role of subsistence factors would necessarily have been mediated by complex societies in any case, not least given their ability to command large labour-forces for major public works that could intensify agricultural productivity. Rather than enlisting natural river courses as in Amazonia, in the Andes some explanations for language expansions have even invoked how humans modified the landscape by road networks, terracing 
and irrigation (Beresford-Jones and Heggarty 2012b). Those could permit population growth and spread languages through demographic pressure, as well as cultural prestige and utility, to explain also the larger populations that speak Andean as opposed to Amazonian languages. Relatively denser populations and state-like structures of control also seem a better explanation for the larger, continuous expanses of territory speaking languages of the same family (although even in the Andes that pattern was still not fully consolidated until late colonial times).

All of this can seem fairly logical, although clearly framed within a preexisting view of supposed basic contrasts in the nature of human societies, their scale and complexity, on either side of the Andes-Amazonia divide. Sceptics might wonder whether this is something of a self-fulfilling prophesy, then. Or it might alternatively be challenged by the latest thinking in Amazonian archaeology that there was no great contrast with the Andes after all. To make either case, though, would nonetheless require alternative explanations for why the major language families on either side of that divide should have come to contrast with each other on multiple dimensions, as well as being so reluctant to venture across it.

\section{Language contact and convergence}

We now switch to the very different dimension of linguistic evidence of interaction and convergence. We follow the scale of increasing intensity of such interactions set out in Chapter 1.2, beginning with the relatively superficial level of loanwords.

\section{Loanwords}

Within either the Andes or Amazonia there are many clear loanwords and striking long-range Wanderwörter. In Amazonia, Epps (2017) explores various Wanderwörter in flora, fauna and cultural terms, such as coca, parrot and knife. In the highlands, the Chipaya language of the Uru family is laced with loanwords from Aymara, and even Mapudungun in Patagonia shares with Quechua occasional words such as challwa (fish) (Golluscio et al. 2009; see http://wold.clld.org/word/ 7211254370820389). And Quechua and Aymara themselves have exchanged far more than occasional words - up to a quarter of their entire vocabularies, in both directions (Cerrón-Palomino 2008).

There are certainly also loanwords that have crossed the Andes-Amazonia divide. Various lowland languages have taken their (higher) numerals from languages of the Andes, for example. The now extinct Chamicuro language (of the Arawak family), in the Amazonian lowlands of northern Peru, takes its numerals above four from Quechua (see https://mpi-lingweb.shh.mpg.de/numeral/ Chamicuro.htm). In the Cavineña language of the Tacanan family in northern lowland Bolivia, the source language of numerals above two is, more unexpectedly, Aymara (which had itself originally borrowed some of the higher numbers from 
Quechua). Further north, Haynie et al. (2014) map variants of the word purutu (beans), suggesting that it originated in Quechua and spread to lowland languages, albeit also through regional Spanish. In reverse, where highland languages have names for Amazonian species and artefacts, it is no surprise that many were borrowed in from lowland languages.

Isolated loanwords between individual language pairs are not much to go on, however. To make well-grounded, generalizable inferences calls for a widespread, systematic survey of exchanges in lexicon across the Andes-Amazonia divide, and a principled approach to interpreting what any patterns found would mean for other disciplines too. Research such as that by Epps (2017) shows the potential for Amazonia, but it has not yet been extended to the Andes - a symptom of the ongoing divide in research itself. Only once comprehensive language databases do span this divide will we really be able to judge whether the loanwords that are widespread within each region are or are not paralleled by as many that did dare to cross the Andes-Amazonia divide.

\section{Structural convergence}

Moving on to deeper interaction effects that extend beyond the lexicon into the sound and grammatical systems of the languages affected, South America is home to 'linguistic convergence areas' (see Chapter 1.3), on different levels of scale and intensity. Epps and Michael (2017) survey multiple localized pockets of intense linguistic convergence in the lowlands, such as the Upper Xingú region and the spectacular case of linguistic exogamy (where there is a convention against marrying somebody of the same native language) in the Vaupés region. In the Andean Altiplano, meanwhile, there is localized and especially intense convergence between the southern varieties of Aymara and Quechua. And this comes on top of a phase of convergence also between the early stages of the entire Quechua and Aymara lineages. This is frequently presented as having brought about the wholesale restructuring of one language on the model of the other (although without consensus on which language played which role). Muysken (2012a) surveys multiple levels of interaction between Andean languages, and the various real-world contact scenarios that they imply.

Zooming out geographically, Quechua-Aymara interaction is actually taken as the core of a wider convergence area in which other Andean languages also participate. Torero (2002, section 6) summarizes the structural characteristics that he takes to define this linguistic area, often termed simply 'Andean'. Like many convergence areas, this one too shows a core-and-periphery pattern. As one moves away from the Central Andes, northwards or southwards, languages tend to share in progressively fewer of the structural characteristics found in the Quechua-Aymara core. Even Quechua itself, for example, lost a few of the core Central Andean characteristics when it spread far north into Ecuador. Similar proposals have been made for a broad 'Amazonian' linguistic convergence area, notably by Derbyshire 
(1987, 311) and by Dixon and Aikhenvald (1999, 7-10), who provide lists of the shared structural characteristics that they see as defining it.

That only brings us to the usual question, however: what of convergence between the Andes and Amazonia? None of the localized convergence zones spans the Andes-Amazonia divide. As for the macro-areas, Dixon and Aikhenvald (1999) go so far as to contrast explicitly their 'Amazonian' structural characteristics with opposing ones that they deem typically 'Andean'. Their presentation has not gone unchallenged, however. Others have objected that not all of Dixon and Aikhenvald's criteria really hold so widely across the languages of Amazonia anyway (see Chapter 3.5; Epps and Michael 2017), and that there is in fact a significant eastwest shift in structural characteristics within Amazonia itself. Rival proposals see the major division through the continent as one that would put western Amazonia if anything together with the Andes, and opposed to eastern South America as a whole (see Chapter 3.5 by Van Gijn and Muysken, and Van Gijn et al. 2017). An intermediate view is that both dividing lines have support in different selections of structural characteristics, which together give a three-way division of Andes versus western Amazonia versus eastern Amazonia. As that suggests, the question is not one that can be resolved by cherry-picking individual characteristics that favour one definition of convergence zones or another. Again, it requires large-scale linguistic databases right across South America, as a basis for more comprehensive, objective and quantified analyses of how the data pattern across the continent. Chapter 3.5 here is founded on precisely such an approach by the authors, which they focus here on our Andes-Amazonia question. Also highly recommended is the balanced overview by Epps and Michael (2017).

\section{Case studies of convergence along the Andes-Amazonia divide}

A further interesting perspective is to be had from languages that represent borderline cases. The Yanesha language (also known as Amuesha) is variously described by Adelaar (2006) as an Arawak language 'of the Peruvian Amazon' or 'spoken in the Andean foothills of Central Peru', and within the Arawak family is deemed to belong to a 'Pre-Andine' branch. Notwithstanding its Amazonian (Arawak) origins, then, Yanesha has encroached somewhat into the highlands, formerly up to elevations of c. 1,800 metres, even if still within cloud-forest. A key motivation may have been to control access to the Cerro de la Sal (Salt Mountain), an important source for the salt trade to Amazonia. (As an aside, it would be intriguing to survey, right along the eastern slopes of the Andes, the exact altitudes at which indigenous languages considered Andean tend to give way to those considered Amazonian.)

The theme of Adelaar's (2006) paper is the clear impact of Quechua on this 'Amazonian' language. That might in itself be taken as Yanesha invalidating the idea of a sharp divide. That said, the interest is precisely because Adelaar sees Yanesha as an exception to a more general rule, of the only 'incidental borrowings 
that affected other Andean and Amazonian languages' across the frontier. And even this exception has its limits. Recall that loanwords in the vocabulary reflect only a more superficial level of interaction than is needed to create the much more far-reaching convergence in language structure between Quechua and Aymara, for example. At that deeper level, Adelaar is clear that 'Quechua impact on Amuesha grammar' was 'very limited when compared with the rather spectacular lexical influx'.

In such cases of contact across the 'frontier', the complementary perspective of human genetics can be all the more informative. Yanesha-speakers do show some Andean admixture, particularly on the male side, but overall they remain genetically more Amazonian than Andean (see Chapter 3.3 by Barbieri, and Barbieri et al. 2014). The linguistic and genetic data concord, then, in diagnosing the Yanesha case as one of contact with highland populations and their languages.

On one view, the case of Yanesha, like the Quechua enclaves in Amazonia, illustrates that in language the Andes-Amazonia divide is by no means complete and hermetic. Nonetheless, both cases also show how in certain respects, deepseated contrasts continue to show through. In the case of the Yanesha, the interactions were certainly not far-reaching enough to obscure that their genetic and linguistic ancestries both remain dominantly and manifestly Amazonian. Speakers of Quechua in Ecuadoran and Peruvian Amazonia also retain their predominantly Amazonian genetic lineage (Sandoval et al. 2016; Barbieri et al. 2017), but in this case European missionaries did force a mismatch by bringing them to switch to a linguistic lineage that is Andean. Even here, though, there are qualifications. For the Quechua that did become established in the lowlands did so at the 'cost' of some degree of assimilation to linguistic characteristics typical of Amazonia, eroding - at least to some extent - their 'Andean' structural profile. Those characteristics, carried over into the originally highland Quechua, mark an enduring substrate from local, Amazonian languages.

\section{On balance}

It was noted in Chapter 1.3 that the very terms 'Andean' and 'Amazonian' as used by linguists were to an extent circular and self-fulfilling, in that the distributions of the main families and convergence patterns have had at least some role in shaping the common linguistic reading of those terms in the first place. That point nonetheless needs to be set in context, by stepping back to an even broader observation. For whichever other regions they do or do not extend to, the linguistic 'Andes' and 'Amazonia' do nonetheless coincide at least with the swift geographical transition from the high Central Andes to the Amazon basin proper. What is more, the linguistic definitions align with each other on both of the basic dimensions of language prehistory that have structured this chapter. The significance of this can only be fully appreciated in a global perspective. For elsewhere worldwide, divergent 
language families and convergent linguistic areas conspicuously do not allow of a single common geographical schema or frontier to divide them into great blocks. The paradigm case is Tibeto-Burman, a single family but whose member languages have converged on either the 'Sinosphere' or the 'Indosphere' type of structural profile (Matisoff 1991, 485-6). That some Tibeto-Burman languages could go one way, and others the other way, is precisely because this one family is dispersed across both sides of the dividing line between those convergence areas. The same goes for languages of the Austro-Asiatic family, across the same convergence frontier. Similarly in Africa, the main areal convergence zones patently do not align with the distributions of the major language families, but crosscut them (Güldemann 2018). Obviously, the powerful processes that shaped the prehistory of human populations and societies have left their clear linguistic effects in South America too. Here, however, those formative processes, divergent as well as convergent, do all appear to have respected the same double frontier: an Andes-Amazonia divide. 